University of Montana

ScholarWorks at University of Montana

8-2005

\title{
Using Airborne Multispectral Imagery to Evaluate Geomorphic Work Across Floodplains of Gravel-Bed Rivers
}

\author{
M. S. Lorang \\ D. C. Whited \\ Richard F. Hauer \\ University of Montana - Missoula, ric.hauer@umontana.edu \\ J. S. Kimball \\ Jack Arthur Stanford \\ The University of Montana, jack.stanford@umontana.edu
}

Follow this and additional works at: https://scholarworks.umt.edu/biosci_pubs

Part of the Biology Commons

Let us know how access to this document benefits you.

\section{Recommended Citation}

Lorang, M. S.; Whited, D. C.; Hauer, Richard F.; Kimball, J. S.; and Stanford, Jack Arthur, "Using Airborne Multispectral Imagery to Evaluate Geomorphic Work Across Floodplains of Gravel-Bed Rivers" (2005).

Biological Sciences Faculty Publications. 301.

https://scholarworks.umt.edu/biosci_pubs/301

This Article is brought to you for free and open access by the Biological Sciences at ScholarWorks at University of Montana. It has been accepted for inclusion in Biological Sciences Faculty Publications by an authorized administrator of ScholarWorks at University of Montana. For more information, please contact scholarworks@mso.umt.edu. 


\title{
USING AIRBORNE MULTISPECTRAL IMAGERY TO EVALUATE GEOMORPHIC WORK ACROSS FLOODPLAINS OF GRAVEL-BED RIVERS
}

\author{
M. S. Lorang,' D. C. Whited, F. R. Hauer, J. S. Kimball, and J. A. Stanford \\ Flathead Lake Biological Station, Division of Biological Sciences, University of Montana, 311 Bio Station Lane, \\ Polson, Montana 59860-9659 USA
}

\begin{abstract}
Fluvial processes of cut and fill alluviation and channel abandonment or avulsion are essential for maintaining the ecological health of floodplain ecosystems characteristic of gravel-bed rivers. These dynamic processes shape the floodplain landscape, resulting in a shifting mosaic of habitats, both above and below ground. We present a new and innovative methodology to quantitatively assess the geomorphic work potential necessary to maintain a shifting habitat mosaic for gravel-bed river floodplains. This approach can be used to delineate critical habitats for preservation through land acquisition and conservation easements, often critical elements of river restoration plans worldwide. Spatially explicit modeling of water depth, flow velocity, shear stress, and stream power derived from surface hydraulic measurements was combined with airborne multispectral remote sensing for detailed modeling of floodplain water surfaces over tens to hundreds of square kilometers. The model results were then combined within a GIS framework to determine potential nodes of channel avulsion that delineate spatially explicit zones across the floodplain where the potential for geomorphic work is the greatest. Results of this study demonstrate the utility of integrating existing multispectral remote sensing data coupled with time-lagged ground-based measures of flow hydraulics to model fluvial processes at relatively fine spatial resolutions but over broad regional extents.
\end{abstract}

Key words: airborne multispectral imagery; floodplain; geomorphology; gravel-bed rivers; river restoration; stream power.

\section{INTRODUCTION}

A new paradigm has emerged over the last decade regarding the biophysical structure and function of rivers that shows floodplains to be centers of biophysical organization throughout the world's river systems (Stanford and Ward 1993, Ward et al. 2002). This view is particularly relevant to gravel-bed rivers where the ecological integrity of accompanying floodplains is intimately linked to the ability of the river to perform geomorphic work (Ward 1997). The dynamics of alluvial processes, particularly cut and fill alluviation and channel avulsion, lead to a shifting habitat mosaic that is essential for sustaining floodplain ecosystem integrity (Stanford 1998).

Large alluvial floodplains of gravel-bed rivers are particularly complex, both above and belowground. The legacy of scour, deposition, inundation, and drought results in an expansive, spatially complex and three-dimensional floodplain mosaic. Lateral, vertical, and longitudinal linkages, through which water and materials flow, are maximized on expansive river floodplains producing inherently high biodiversity and biocomplexity (Ward et al. 1999). Under natural conditions, biodiversity and biocomplexity are maximized

Manuscript received 25 September 2003; revised 25 August 2004; accepted 7 September 2004; final version received 3 November 2004. Corresponding Editor: J. Baron.

${ }^{1}$ E-mail: mark.lorang@umontana.edu on gravel-bed river floodplains because of the convergence of aquatic and terrestrial biotic assemblages at multiple spatial and temporal scales, and because convergence trajectories are regularly disturbed by flooding (Ward et al. 1999). The biophysical linkages that characterize natural floodplains are critical to sustained anadromous and resident salmonid populations, as well as other important components of a floodplain ecosystem (Naiman 1998, Ward et al. 2002).

Several studies from across western North America have revealed progressive declines in the extent and health of floodplain gallery forests (Bradley and Smith 1986, Braatne et al. 1996). The primary causes of these declines have been related to dams, water diversions, and the clearing of floodplain habitats for agricultural use and livestock grazing (Rood and Mahoney 1990, Rood et al. 1995, Mahoney and Rood 1998). Globally, floodplains are threatened by degradation from flow regulation, habitat alteration, domicile encroachment, agricultural cultivation, invasive nonnative species, and pollution. There is an urgent need for floodplain restoration through conservation easements and purchases of critical habitat to protect remaining intact floodplains (Tockner and Stanford 2002).

The river can do much of the work of restoration, but effectiveness of this river restoration protocol largely depends on the degree to which regulated rivers are allowed to approach natural flow conditions and reoccupy historical floodplains (Stanford et al. 1996, 

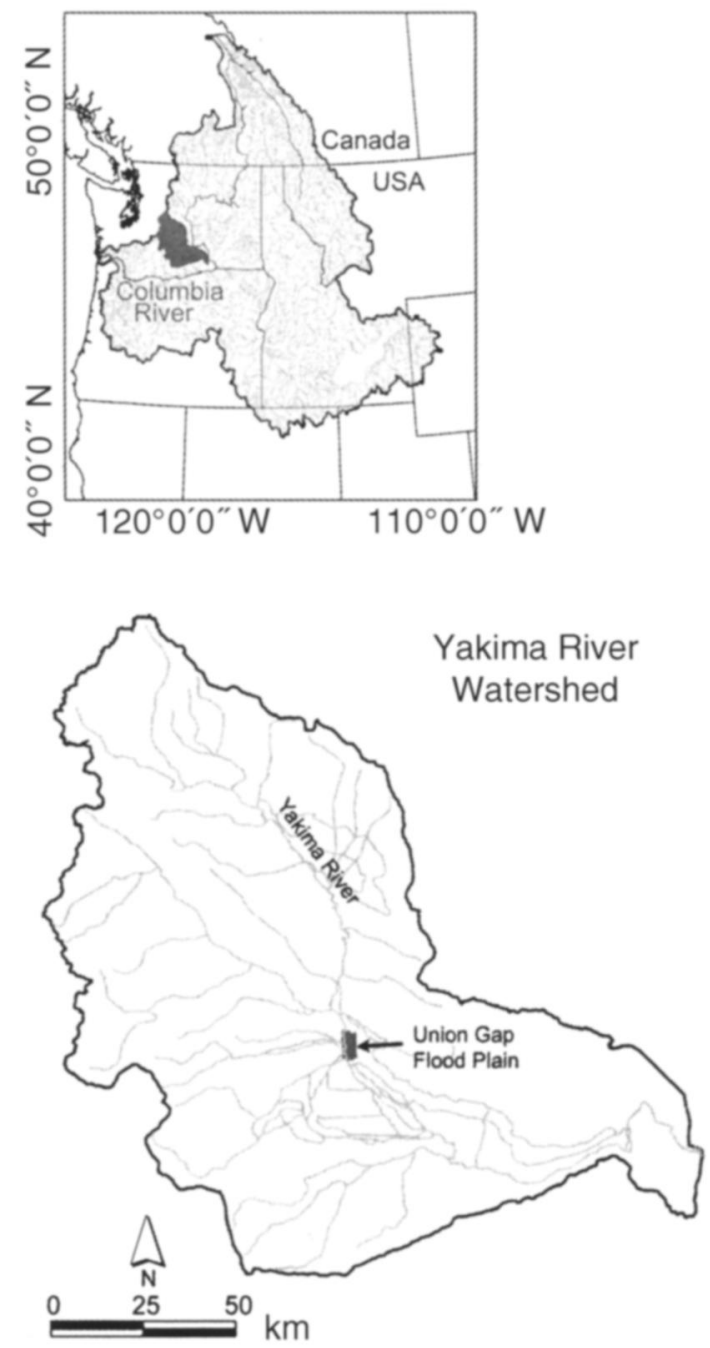

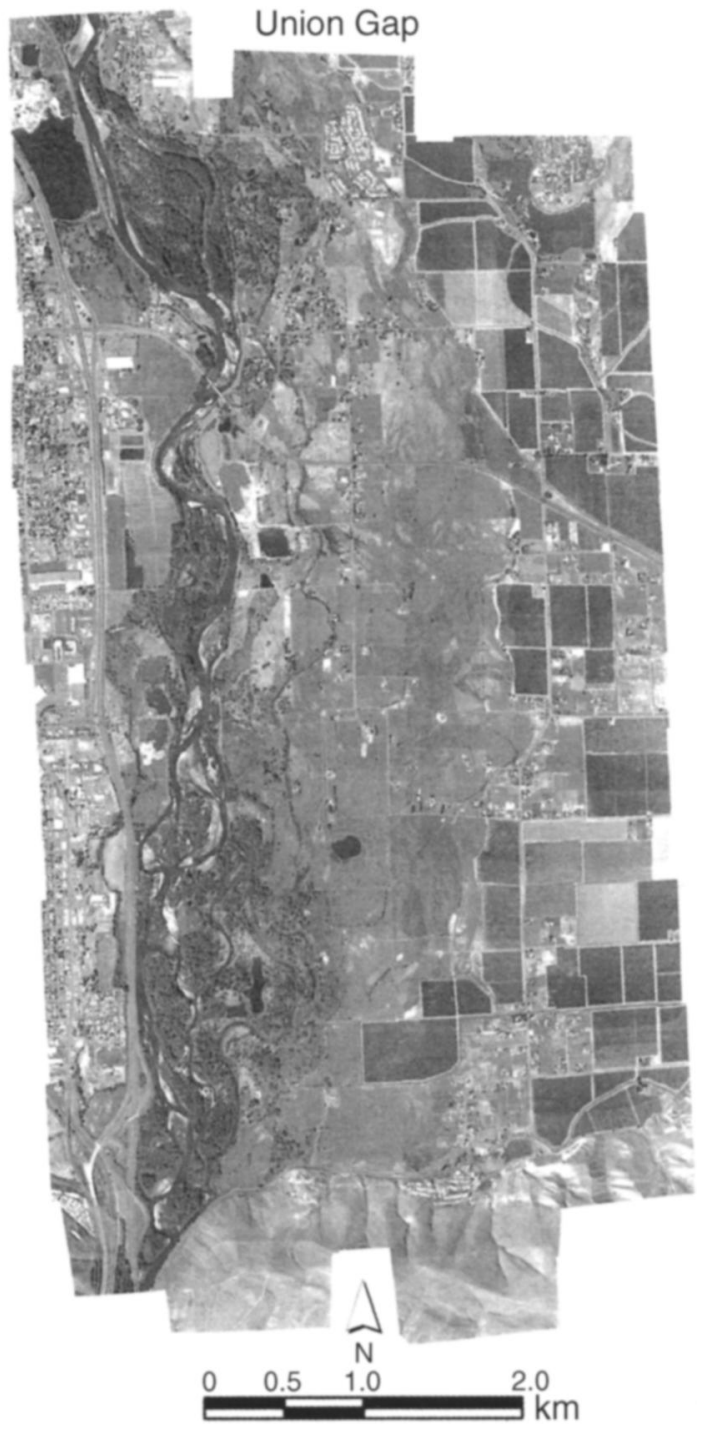

FIG. 1. The figure shows the extent of multispectral imagery acquired for Union Gap floodplain reach and location within the Columbia and Yakima River drainage basins, northwestern United States and Canada.

Richter and Richter 2000). These activities will require the development of new and robust methodologies to identify, assess, and monitor floodplain areas with the greatest potential for a renewed shifting habitat mosaic to exist. We present such a methodology below using a combination of field measurements of water depth and flow velocity coupled to spectral reflectance patterns captured with airborne multispectral imagery.

\section{STUdy AREA}

We studied the Union Gap floodplain (Fig. 1) along the sixth order Yakima River in central Washington, USA $\left(46^{\circ} 33^{\prime} \mathrm{N}, 120^{\circ} 27^{\prime} \mathrm{W}\right)$. The reach is $\sim 8 \mathrm{~km}$ in length and $2-3 \mathrm{~km}$ wide, with 93 ha of water surface and $110 \mathrm{~km}$ of river edge during base flow conditions. The floodplain has been severely altered by gravel mining, levees, and urban encroachment. In spite of these disturbances, floodplain processes such as cut and fill alluviation and channel avulsions continue to reshape some areas of the floodplain, creating floodplain habitats such as spring brooks, isolated ponds, and wetlands. Several federal, state, and local county agencies are interested in the preservation of critical floodplain habitats within the Union Gap reach through land acquisition and conservation easements.

\section{METHODS}

\section{Image acquisition}

Airborne multispectral (blue, $0.46-0.55 \mu \mathrm{m}$; green, 0.52-0.61 $\mu \mathrm{m}$; red, 0.61-0.70 $\mu \mathrm{m}$; near-infrared, 0.78$0.92 \mu \mathrm{m})$ digital imagery was acquired on 24 August 1999 for the Union Gap floodplain on the Yakima River. The digital imagery was acquired at a $1-\mathrm{m}^{2}$ resolution. 
Discharge at the time of image acquisition was $74 \mathrm{~cm}$ measured at the Terrace Heights gauging station located $\sim 1 \mathrm{~km}$ upstream from our study reach. The remote sensing data were acquired using an ADAR System 5500 digital camera (Positive Systems, Whitefish, Montana, USA) flown on-board a light aircraft. A digital image mosaic (Fig. 1) was created for the floodplain image using Digital Image Made Easy (DIME) software (Positive Systems, Whitefish, Montana, USA), which uses a semiautomated textural analysis of overlapping images to assemble large amounts of spatial data into a single mosaic. The digital image mosaics of the floodplain were then georeferenced to a United States Geological Survey (scale - 1:2400) Digital Ortho-Photo database. These remote sensing data were then used for spatially explicit classification of flow velocity, water depth, and vegetation cover for the entire floodplain reach.

\section{Field measurements of depth and flow velocity}

A Sontek RS3000 Acoustic Doppler velocity-Profiler (ADP, Sontek/YSI, San Diego, California, USA) was used to acquire detailed water depth and vertical profile measurements of flow velocity along channel reaches within the study floodplain. The ADP data were obtained on 23 April 2001, when river discharge was 59 $\mathrm{cm}$ measured at the Terrace Heights gauging station. The ADP uses three transducers to generate a $3 \mathrm{MHz}$ acoustic pulse into the water. As the sound travels through the water, it is reflected in all directions by particulate matter (e.g., sediment, biological matter) being transported with the flow. The transmitted energy is most strongly reflected from the bottom substrate providing a measure of water depth. Some of the energy reflected from particles being carried with the flow returns to the transducers with a frequency change, and the processing electronics measure that Doppler shift, which is directly correlated to the velocity of the water. By measuring the return signal at different times following the transmit pulse, the ADP measures water velocity at different distances from the transducer, from just below the water surface to the bottom. This results in a measured velocity profile and depth of the water column. The profile of water velocity is divided into a series of individual $15 \mathrm{~cm}$ deep cells from top to bottom, where the average of the return signals for 5-s time intervals are measured for each cell. The ADP operates using three transducers generating beams with different orientations relative to the flow of water. The velocity measured by each ADP transducer is along the axis of its acoustic beam. These beam velocities are converted to XYZ (Cartesian) velocities using the relative orientation of the acoustic beams, giving a 3-D velocity field relative to the orientation of the ADP. Since it is not always possible to control instrument orientation, the ADP includes an internal compass and tilt sensor to report 3-D velocity data in Earth (EastNorth-Up or ENU) coordinates, independent of instru-

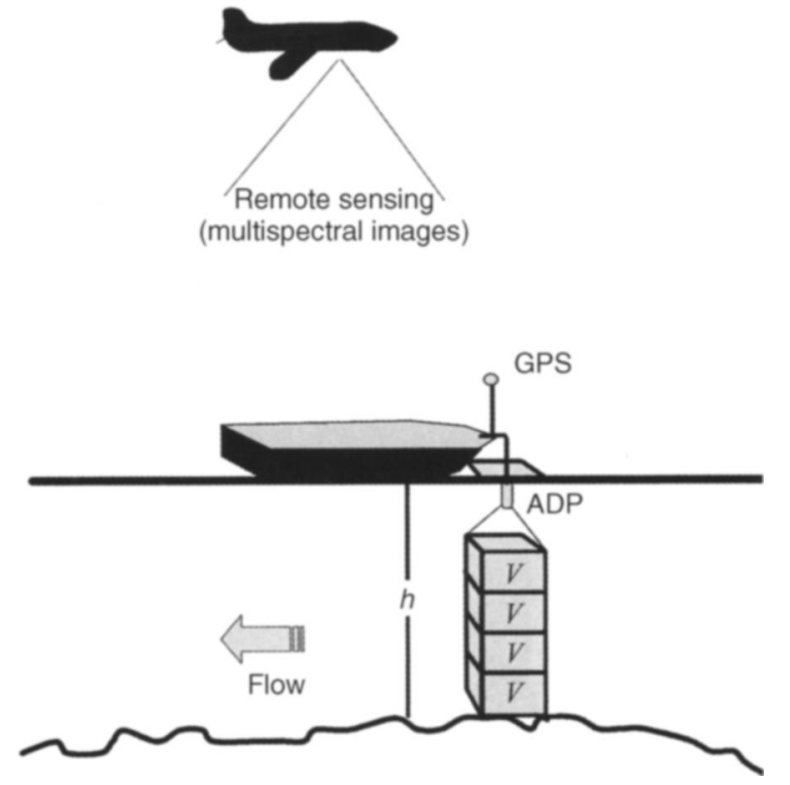

FIG. 2. A schematic showing the correlation between multispectral imagery, over a square area of water surface, with flow velocity $(V)$ and depth $(h)$ data measured with the ADP (Acoustic Doppler velocity Profiler). Velocity was measured in discrete bin intervals throughout the water column and then averaged to determine $V$.

ment orientation. Hence, it is possible to determine the mean flow velocity in separate cells through the water column oriented perpendicular to the flow field.

We deployed the ADP from the front of a small jetboat with both velocity profile data and depth data correlated spatially by linking a GPS (Global Positioning System) receiver colocated with the position of the ADP (Fig. 2). During data acquisition the ADP was maneuvered back and forth across the channel to obtain data from as full an array of aquatic habitats, depths, and velocities as possible. Both the ADP and GPS data were recorded simultaneously on a field laptop computer. The ADP data were then processed to create an integrated velocity value (average velocity for an individual ADP profile) as well as a depth value for each GPS location.

\section{Image and field data collection inconsistencies}

We used archived imagery from a previous project on the Union Gap floodplain coupled with ADP data to model depth and velocity throughout the floodplain reach. Although there was a two-year gap between the acquisition of imagery and the subsequent field data, the amount of geomorphic change was minimal and the discharges were similar in comparison to peak discharges that typically result in geomorphic work (Fig. 3 ). The winter of 1996-1997, two years prior to the image acquisition date, was dominated by large magnitude and duration flooding (Fig. 3). Those flood events greatly exceeded bankfull discharge levels. Two 


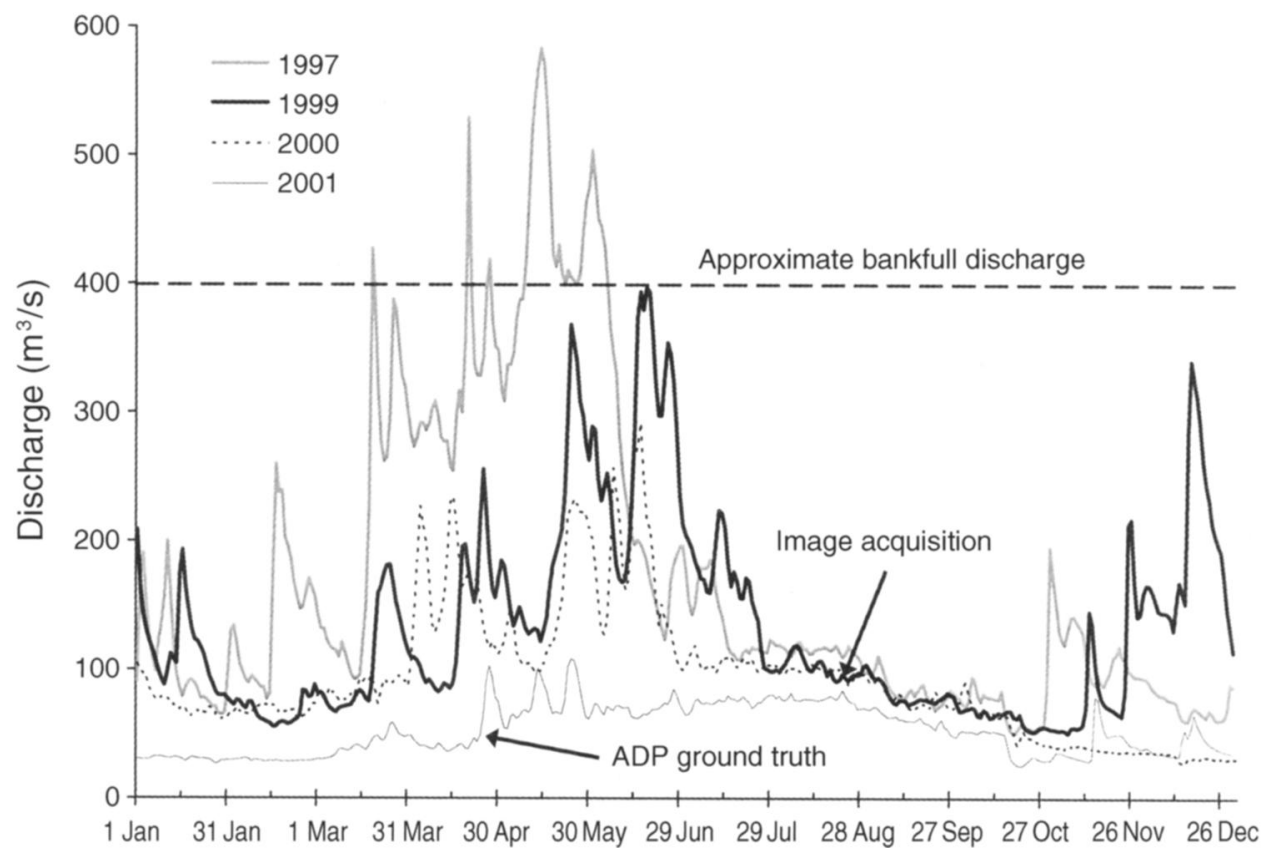

FIG. 3. The figure shows a comparison between a flood of record discharge (1997) and the timing of image acquisition in 1999, along with the 2001 ADP ground truth data with the discharge between those data collections. All discharge data come from the USGS gauging station number 12500450 located just below the Union Gap reach, Washington State, USA.

other near bankfull discharge events occurred in May and June 1999. These flow events exceeded broad geomorphic thresholds and played a significant role in setting the geophysical template for the Union Gap reach prior to image acquisition in August 1999. Conversely, no large magnitudes or long duration discharge events occurred in 2000 and 2001 prior to acquisition of the hydraulic ground truth data that could have resulted in significant geomorphic changes relative to those that occurred in 1996 and 1999 (Fig. 3).

Ideally imagery and ground truth data should be collected within the same time frame. However, flow conditions were similar and no major geomorphic work occurred between the time of image acquisition and the collection of ground truth data, so it is reasonable to believe that measures of depth and velocity were similar. Minor perturbations in depth and flow velocities occurred due to rearrangement of large wood, lateral erosion, and bar deposition over time, but these changes were minimal and in isolated areas.

To verify the analysis of the hydrologic record, we used a high resolution satellite image from 27 August 2000 (similar discharge to the 1999 image) to compare inundation extent to the 1999 image. Between 1999 and 2000 , there was only a $4 \%$ increase in inundation extent and no channel movement. By overlaying the 2001 coordinates of the main thalweg on the 1999 image we determined the position of the main channel had not changed.

Both the acquisition of multispectral imagery and ADP ground truth data occurred during similar base flow conditions (Fig. 3). The difference in discharge between the acquisition of imagery and the subsequent field data amounted to only a $10-\mathrm{cm}$ difference in stage. This is less than the resolution at which we were able to classify water depth and model topographic elevations across the floodplain. Thus, the spatial patterns of water depth and flow velocities measured in 2001 were within the range of actual depth and velocities values that occurred during image acquisition in 1999. We demonstrate this thoroughly and discuss the ramifications to model results in the section, (Methods: Assessment of classification error). By carefully examining discharge records, geomorphic changes, and collecting field data at similar flow conditions, we feel archival imagery can be successfully used to model depth and velocity, as well as other floodplain habitats.

\section{Classifying flow velocity and water depth}

Water depths and flow velocities were modeled based on correspondence between these variables and surface water spectral reflectance patterns captured by the airborne multispectral digital imagery. The water surface spectral reflectance patterns were directly related to surface water roughness and color. The technique required three steps: (1) classification and extraction of surface water features from the imagery, (2) separation of off-channel and main channel habitats, and (3) classification of channel depth and flow characteristics by statistical relationships established between spectral reflectance characteristics and corresponding ground truth data. The near-infrared band and a normalized 
difference vegetation index (NDVI) were used with a supervised classification method to isolate and extract water surfaces from surrounding land areas. These methods exploit the relatively low near-infrared reflectance characteristics of water and large sensitivity of the NDVI to photosynthetic biomass to isolate open water surfaces from the surrounding landscape. The extracted water imagery was then converted from raster to vector format to distinguish main channel and offchannel habitats. Off-channel habitats had mud or sand/ silt substrate and a unique spectral signature relative to the main channel, which was dominated by cobble substrate. Main and off-channel features were treated separately for classifying depth and flow characteristics measured in the field with the ADP.

An unsupervised classification of the water body imagery was applied to differentiate water depth and flow categories. An unsupervised clustering approach (ISODATA, Iterative Self-Ordering Data Analysis, Tou and Gonzalez [1977]) was used to generate similar clusters of spectral reflectances (Fig. 4). The clusters were aggregated to four depth categories $(<0.6,0.6-$ $1.2,1.2-1.8$, and $>1.8 \mathrm{~m}$ ) and four velocity categories $(<0.6,0.6-1.2,1.2-1.8$, and $>1.8 \mathrm{~m} / \mathrm{s})$, based on the ADP survey data (Fig. 5). Only a subset of the ADP data (543 points) was used to assign the appropriate depth and velocity categories; the remaining data were used to assess the accuracy of the classification.

This methodology followed an approach developed by Whited et al. $(2002,2003)$ using a comparably small number of point measures (200) of water depth and flow velocity obtained with a total station and handheld flow meter. Using the ADP deployed from a boat over a wide range of flow and depth conditions, we obtained 1160 measures of water depth and integrated current velocity, which allowed us to far more accurately estimate the remote sensing classification of these parameters.

\section{Assessment of classification error for flow velocity and water depth}

The relative accuracy of the image classification was determined by comparing ADP subset data withheld from the supervised classification process with corresponding depth and velocity categories of the classified imagery on a pixel-by-pixel basis. Overall accuracy of these results averaged $66 \%$ for flow velocity and $73 \%$ for water depth (Table 1). Errors related to reflectance anomalies of individual pixels within areas of similar flow velocity result from the situation where an individual pixel could have a false classification and be colocated with a ground truth ADP measure. Conversely, individual ADP measures of flow velocity could be slightly higher or lower than the surrounding water due to submerged logs, boulders, or other geomorphic features that lower the overall accuracy assessment on a pixel-by-pixel basis. ADP measurements collected along sharp $(<1 \mathrm{~m})$ horizontal flow gradients also low- ered the overall assessment accuracy. In addition, both velocity and depth were averaged over a 5-s interval, which can create error when transitioning from fast to slow water. Thus, depending on flow and geomorphic conditions, an individual ADP profile could be an average of multiple flow and depth conditions for a given GPS location.

The level of accuracy of the real time GPS data varied as a function of the number and position of satellites in the sky during data acquisition. The 3- to 4-m offset can result in a mismatch between ADP profile and spectral reflectance measurements. This error was obvious for ADP data that plotted out of the channel on the bank; these were removed from the analysis. However, it was not possible to exclude ADP data points collected in a tranquil eddy that plot in close neighboring fast runs. Some difference in flow-field surface features may have been a function of different discharge between acquisition of the remote sensing data and the collection of ADP data, as well as morphological changes that may have occurred between the collection times of the data as noted in the discussion previously.

In spite of the various potential sources of pixel-bypixel error, relationships of depth and flow (i.e., pools, riffles, rapids, and shallows) were correctly identified in surface water habitats (Fig. 5). Overall, the results of the image classifications were adequate, since differences between surface measurements and classification results were associated with isolated pixels that were negligible at the scale of river channel hydraulics modeled. Pixel-by-pixel accuracy could be improved by broadening our depth and flow categories, but that would greatly reduce the spatial resolution for modeling stream power.

In order to delineate floodplain areas with the greatest potential for a renewed shifting habitat mosaic, we used the results from classifying water depth, flow velocity, and floodplain topography from the multispectral imagery to determine the spatial distribution of stream power and shear stress. The following discussion explains those procedures and the underlying assumptions, limitations, and advantages that are inherently intertwined in the methodology.

\section{Modeling stream power}

Stream power $\left(P, \mathrm{~W} / \mathrm{m}^{2}\right)$ is a fundamental measure of the potential of a river to perform work such as bank erosion and sediment transport resulting in specific outcomes such as channel avulsion (Bagnold 1966). Stream power $P$ at a specific location was calculated with the following equation using estimates of slope $S$, water depth $h$, and flow velocity $V$ :

$$
P=\rho g h S V
$$

where $\rho$ is the density of water and $g$ is a constant $(9.81$ $\mathrm{m} / \mathrm{s}^{2}$ ) representing gravitational acceleration (Lorang and Hauer 2003). Embedded in Eq. 1 is the equation 


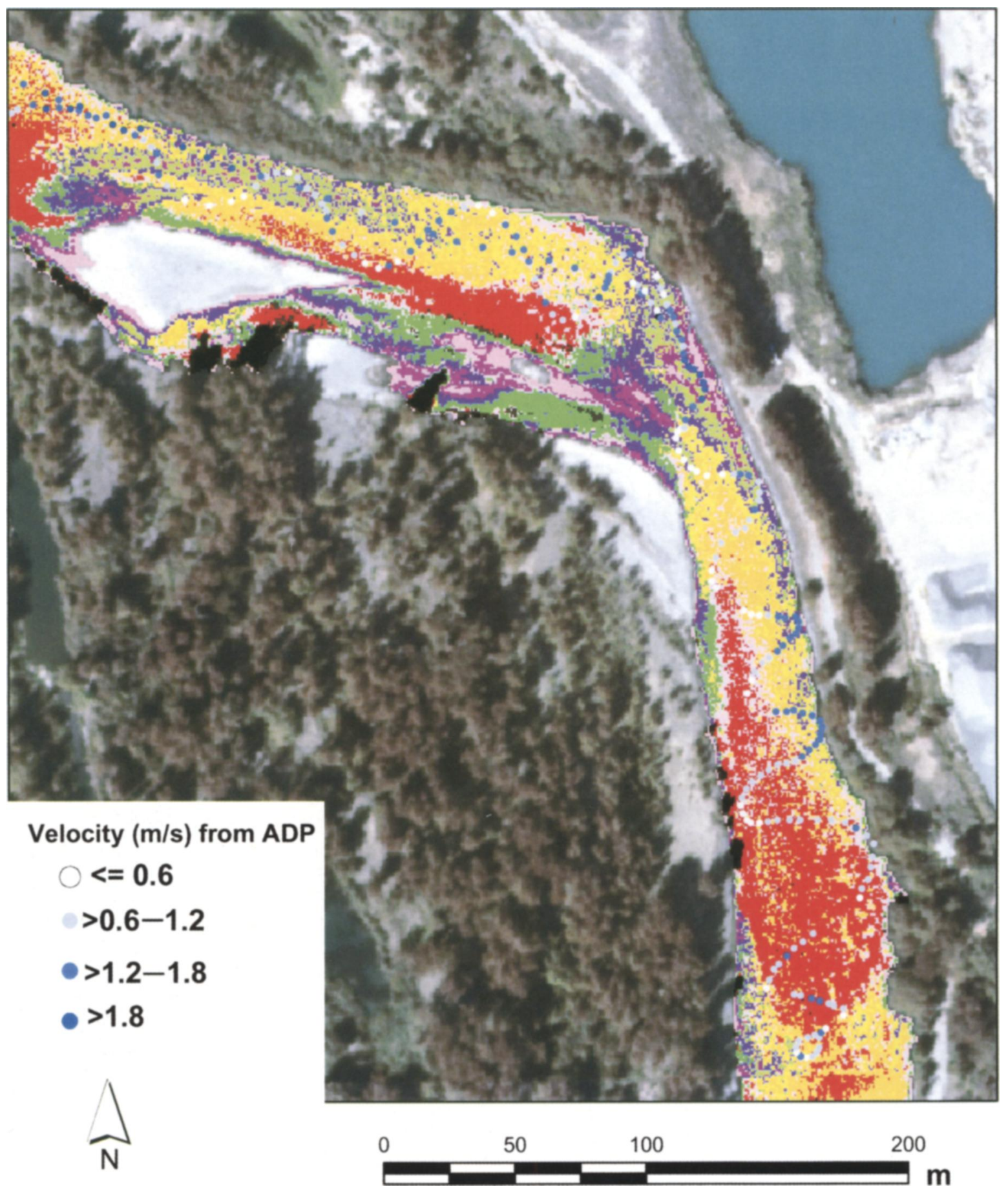

FIG. 4. Unsupervised classification of pixel spectral variance for the water surface from a multispectral image taken 24 August 1999. The GPS positions for velocity measures taken with the ADP are superimposed on the image as a series of blue dots delineating the ship track. Flow velocity is scaled as shades of blue for each dot.

for shear stress, $\tau_{0}$ acting on a particular unit area of the streambed

$$
\tau_{0}=p g h S .
$$

Thus, as water depth, $h$, or the down slope component of gravity $(g S)$ increases so does the potential $\tau_{0}$ at a single depth point. Likewise, stream power will also increase as $\tau_{0}$ increases and as flow velocity, $V$ increases.

Flow velocity results from a balance between the energy gradient and frictional resistance from the channel bed and banks and other elements of flow resistance 
like large wood. That balance is the friction slope $S_{\mathrm{f}}$ and is defined as the head loss due to boundary friction along some length of the stream reach (Lorang and Hauer 2003). The friction slope can differ from the water surface slope and bed slope because of energy losses due to acceleration and deceleration in a contracting or expanding reach, or with discharge as a function of different levels of flow resistance (Lorang and Hauer 2003). It is difficult and time consuming to actually measure $S_{\mathrm{f}}$; thus, we used topographic slope as a first order approximation in the calculation of $\tau_{0}$. This is a reasonable approximation as long as the possible discrepancy of actual shear stress is kept in mind when interpreting results (Lorang and Hauer 2003). The spatial distribution of shear stress for any discharge can be estimated as a function of channel geometry without the difficulties associated with estimating variation in flow resistance.

Slope for calculating $\tau_{0}$ was estimated with a $30-\mathrm{m}$ resolution USGS digital elevation model (DEM) that provided an estimate of general slope inflections along the river rather than the actual slope of the water surface. Some steeper slopes associated with rapids at the ends of bars and pool-riffle sequences were not completely resolved with a 30-m DEM. However, in spite of the coarse scale, the estimates for the spatial distribution of general (e.g., high and low) stream power potential along the floodplain study corridors were sufficiently accurate for the scale at which we were working (Fig. 6). This occurs because the classified airborne multispectral data reflects those areas that have different local flow velocities and depths but similar general slopes (Fig. 5). The incorporation of flow velocity and water depth measured from the remote sensing data can more precisely delineate the spatial differences in stream power at the discharge associated with image acquisition. In this way we were able to overcome some of the inherent shortcomings of calculating stream power by using an independent measure of flow velocity and water depth determined ultimately from the spectral reflectance patterns captured with the multispectral imagery. The actual spectral reflectance patterns captured by the imagery were directly related to water surface roughness that was a product of water depth and flow velocity, which in turn reflected local differences in friction slope gradients.

Once we determined the stream power for each within-channel pixel of the multispectral image, we plotted each pixel based on the degree of departure from the mean mapped as standard deviations of high stream power (Fig. 6). Displaying stream power in this manner showed spatially where along the river corridor stream power was high relative to the mean. The combination of slope, depth, and flow velocity provided sufficient detail to distinguish stream power spatial variation along the river corridor through this floodplain reach. We expected areas with localized zones of relatively high stream power potentially were areas where a chan-
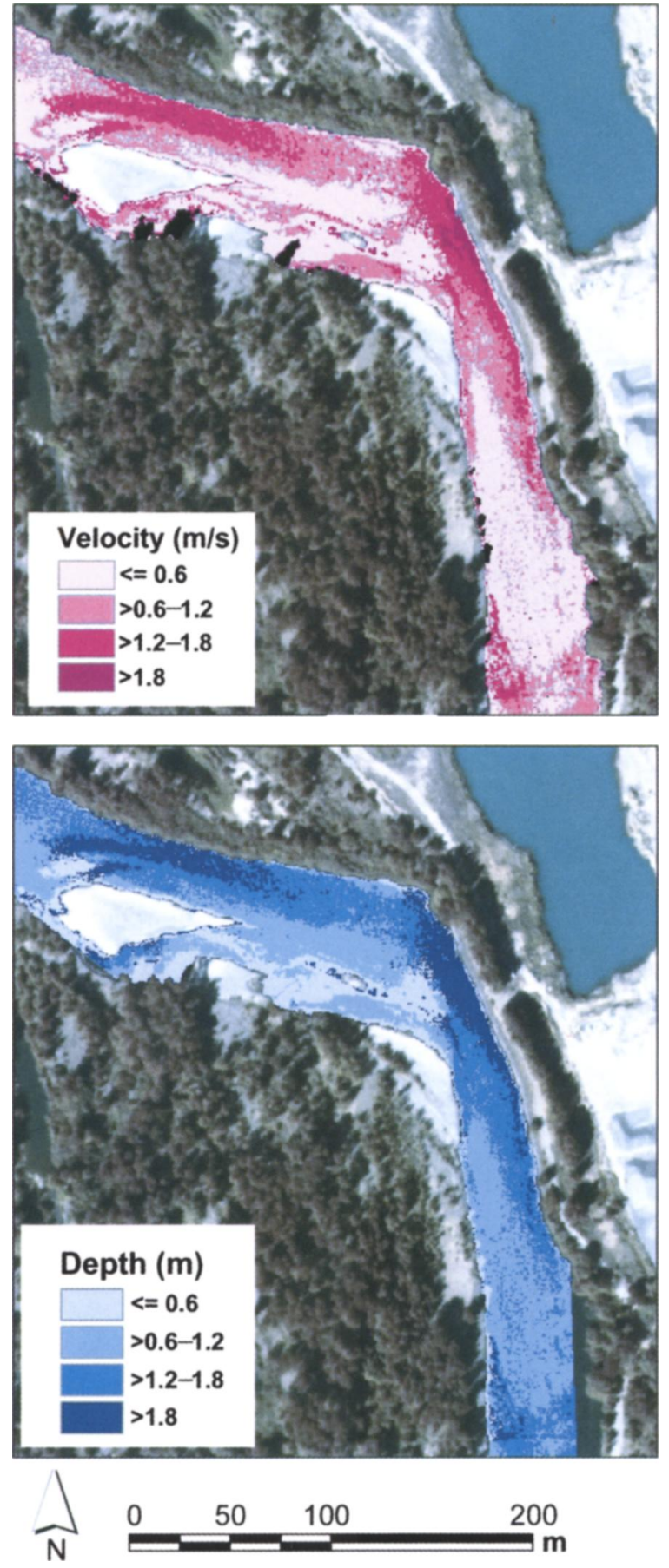

FIG. 5. Supervised classification of flow velocity (top) and water depth (bottom).

nel avulsion was likely to occur. Hence, it provided a valuable tool for predicting the location of channel avulsions as well as where processes of cut and fill alluviation were apt to be more active. This modeling effort provided a first step in assessing floodplain areas with the highest stream power, and hence, potential for geomorphic work to be accomplished. 
TABLE 1. Error matrix describing the accuracy of the classifications for depth and velocity.

\begin{tabular}{|c|c|c|c|c|c|c|}
\hline \multirow[b]{2}{*}{ Classified data } & \multicolumn{5}{|c|}{ Reference data } & \multirow{2}{*}{$\begin{array}{l}\text { User's } \\
\text { accuracy }\end{array}$} \\
\hline & $0-0.6$ & $0.6-1.2$ & $1.2-1.8$ & $>1.8$ & Total & \\
\hline \multicolumn{7}{|l|}{ Velocity $(\mathrm{m} / \mathrm{s})$} \\
\hline $0-0.6$ & 15 & 2 & 3 & 0 & 20 & 0.75 \\
\hline $0.6-1.2$ & 5 & 134 & 29 & 10 & 178 & 0.75 \\
\hline $1.2-1.8$ & 22 & 92 & 200 & 16 & 330 & 0.61 \\
\hline$>1.8$ & 4 & 18 & 11 & 56 & 89 & 0.63 \\
\hline Total & 46 & 246 & 243 & 82 & 617 & \\
\hline Producer's accuracy & 0.33 & 0.54 & 0.82 & 0.68 & & \\
\hline Overall accuracy & & & & & & 0.66 \\
\hline \multicolumn{7}{|l|}{ Depth (m) } \\
\hline $0-0.6$ & 120 & 39 & 13 & 3 & 175 & 0.69 \\
\hline $0.6-1.2$ & 45 & 260 & 21 & 5 & 331 & 0.79 \\
\hline $1.2-1.8$ & 0 & 3 & 23 & 4 & 30 & 0.77 \\
\hline$>1.8$ & 0 & 12 & 23 & 46 & 81 & 0.57 \\
\hline Total & 165 & 314 & 80 & 58 & 617 & \\
\hline Producer's accuracy & 0.73 & 0.83 & 0.29 & 0.79 & & \\
\hline Overall accuracy & & & & & & 0.73 \\
\hline
\end{tabular}

Note: The producer's accuracy shows errors of omission (i.e., spectra that were incorrectly excluded from their proper category), while the user's accuracy shows errors of commission (i.e., spectra that were incorrectly included in another category).

\section{Creating a high resolution digital elevation model (DEM)}

Critical features such as backwater channels, spring brooks channels, and isolated ponds were missed or oversimplified by the USGS 30-m DEM. Similarly, it was not feasible to use traditional survey methods to adequately measure the topography over many kilometers of river corridor. To obtain detailed topographic information, we combined focused topographical survey information with the airborne multispectral data to assign relative elevations to classified floodplain cover type features.

Floodplain cross-sectional topographic surveys were conducted through riparian vegetation communities associated with the main river channel in order to sample a broad range of topography (slope, elevation) across as many cover type features as possible. Other features captured by these surveys included relative elevations between gravel bars, water surface, and bank top elevations throughout the floodplain reach. Supervised classifications of the airborne multispectral remote sensing imagery revealed major land cover features, including vegetation (e.g., grassland, shrubland, forest), side channels, spring brooks, cobbles, terraces, and other floodplain features. The survey data was overlaid on the various classified cover types and assigned a relative elevation to the main channel, as well as typical slope values, to characterize the transition from one cover type to the next. Water surface elevation in the main channel was set to zero in all cross sections and all other cover types were assigned relative elevations ( \pm change in elevation from the main channel). Thus, relative elevations and slopes, both across and between cover types, were assigned to the identified major land cover features classified from the multi- spectral imagery. With this combination of survey data and multispectral imagery we were able to produce a high resolution DEM of the floodplain (Fig. 7, left panel).

\section{Modeling shear stress across the floodplain}

Water depth and slope are the only variables needed to estimate channel shear stress. Therefore, using the higher resolution DEM we were able to use existing stage-discharge relationships to simulate flood inundations for various discharges. This allowed us to delineate floodplain areas likely to be inundated and reworked during potential flooding events.

Floodplain inundation was modeled at $10-\mathrm{cm}$ stage increments using the higher resolution DEM and existing stage-discharge relationships. We compared modeled flood inundation, with a georectified digital photograph of inundation taken during a 1996 flooding event and found that $72 \%$ of the modeled inundated area overlaps with the 1996 flood (Fig. 7, middle panel). In some areas the modeled inundation corresponded much more closely with the observed 1996 floodplain inundation. Those areas with lower correlation were associated with changes in the shallow water environments resulting from either gravel deposition on existing bars that occurred during the 19961997 flood prior to the acquisition of the multispectral imagery or slope errors associated with our DEM. Note these areas occurred in zones of low stream power; therefore the errors did not affect the location or patterns of high stream power that are the patterns that drive the analysis of potential geomorphic work.

Once flood inundation was simulated, we calculated water depths across the various floodplain features for each stage increment and then shear stress using the 


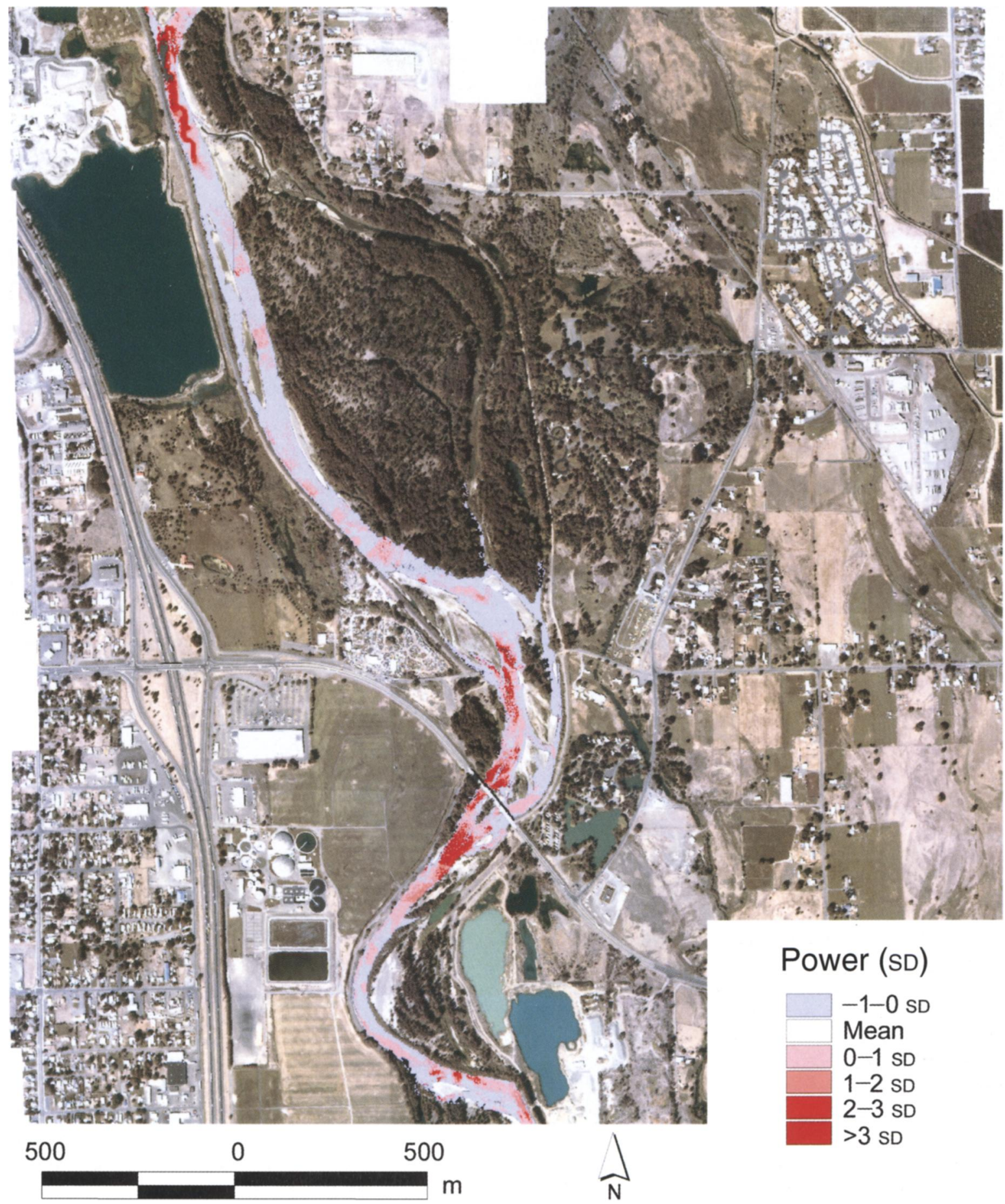

FIG. 6. A plot of the spatial distribution of stream power standard deviation, within the main channel of the Union Gap Reach, modeled with a GIS using multispectral imagery. ADP data and slope are derived from USGS $30-\mathrm{m}^{2}$ DEM data.

water depths and slope estimates for the floodplain (Fig. 7, right panel). Displaying the spatial distribution of shear stress in this manner allowed comparison between shear stress in the main channel and shear stress in flooded off channel areas for any specified stage level of discharge. Where shear stress in an off channel has a similar magnitude as in the main channel (see Fig. 7 , right panel), it is likely that similar levels of geomorphic work can be accomplished. This approach was used to assess potential shear stress at a bankfull discharge, where bankfull corresponds to the elevation defined by forested boundaries, for all potential con- 

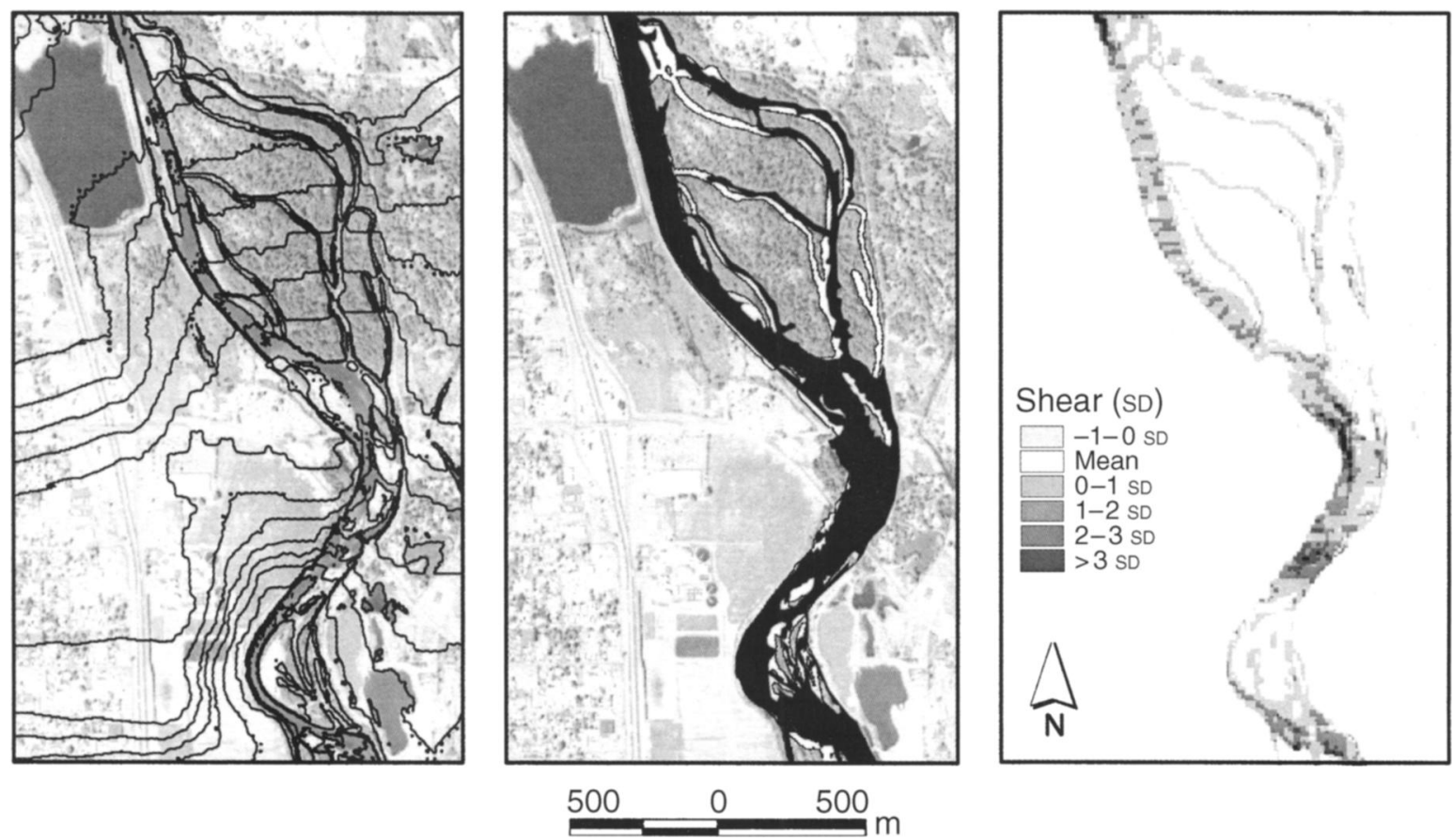

FIG. 7. A multispectral image showing an overlay of modeled topography (left panel); a comparison of a modeled flood discharge (black) to actual flood of 1996 (light gray) based on the modeled topography (middle panel); and the spatial distribution of shear stress in the floodplain corresponding to the modeled flood discharge shown in the middle panel (right panel).

nected flood channels. For most sites, any further increase in stage would result in a dramatic increase in the top width of the channel, defining a bankfull condition.

\section{RESUlts}

\section{Zonal delineation of potential geomorphic work}

Stream power and shear stress modeling results were overlaid (Fig. 8) to identify potential channel avulsion nodes and further delineate areas of the floodplain with high, moderate, or low potentials for geomorphic work. Areas where flood flows connect floodplain secondary channels with the main channel in a zone of high stream power had the highest potential to form an avulsion node (Fig. 8). Areas where flood flows connected floodplain secondary channels with the main channel in a zone of relatively low stream power but adjacent to the outside of a channel bend also had a high potential for an avulsion node to form (Fig. 8). Those areas where flood flows connected floodplain secondary channels with the main channel in a zone of low relative stream power without being adjacent to an outside bend of the main channel had a relatively lower potential to form an avulsion node (Fig. 8). Connecting the avulsion node at the top to the lateral extent of flooding and nodes of convergence where the flood channels joined back to the main channel provided a defining limit for zones of potential geomorphic work (Fig. 8).
It was possible to define avulsion nodes, the lateral extent of flooding, and nodes of flow convergence by using the modeling results for stream power and shear stress at a bankfull condition. These attributes provided a means for delineating floodplains into zones of high and medium potential for geomorphic work. Once the zonal delineation was complete the spatial patterns of stream power and shear stress results were examined further to identify fluvial geomorphic processes important to making management decisions, as well as evaluating ecological responses.

\section{DisCUSSION}

The prediction of avulsion nodes was used to identify key areas where existing levies could be breached to reconnect floodplains with the main river channel. The spatial mapping of stream power and shear stress was also used to predict hot spots of potential bank erosion and the spatial extent of depositional zones. Bank erosion is an important process for maintaining an adequate floodplain sediment supply. Coupling that information with knowledge of depositional zones provided a basis for a sediment budget analysis, including quantification of potential channel widening and incision impacts related to gravel mining practices, bank armoring, and bridge and road construction, as well as the removal of such structures. All of these practices impact the supply of gravel, which ultimately effects the formation of new floodplain habitat. The ability to 


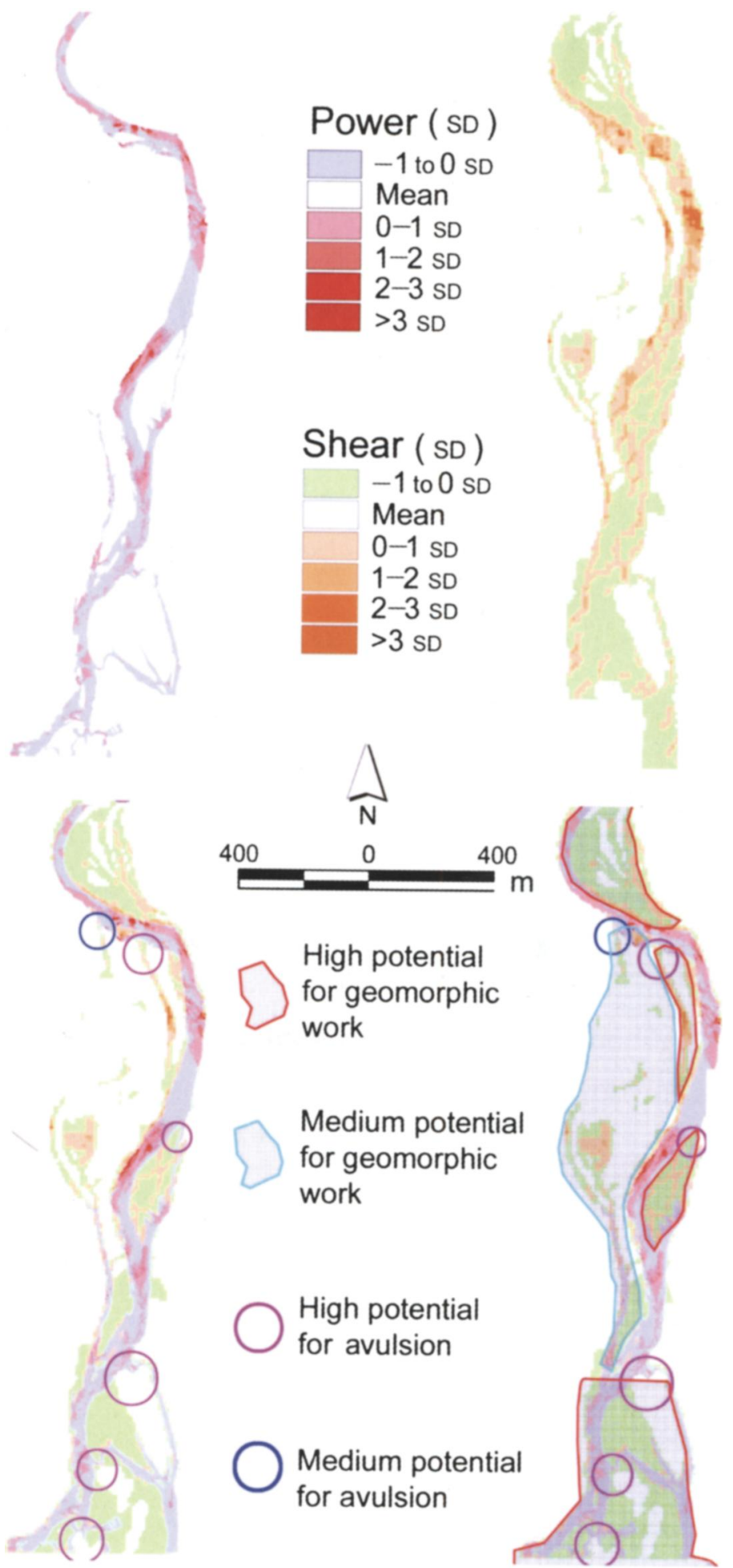

FIG. 8. A schematic of the methodology used to combine the stream power modeling with that of shear stress to delineate zones of potential geomorphic work. The top left panel represents stream power at a base flow discharge. The top right panel represents modeled shear stress at bankfull discharge. The lower left panel shows an overlay of stream power and shear stress that together define potential avulsion nodes. The lower right panel shows the delineation of areas with high and moderate potentials for geomorphic work. 


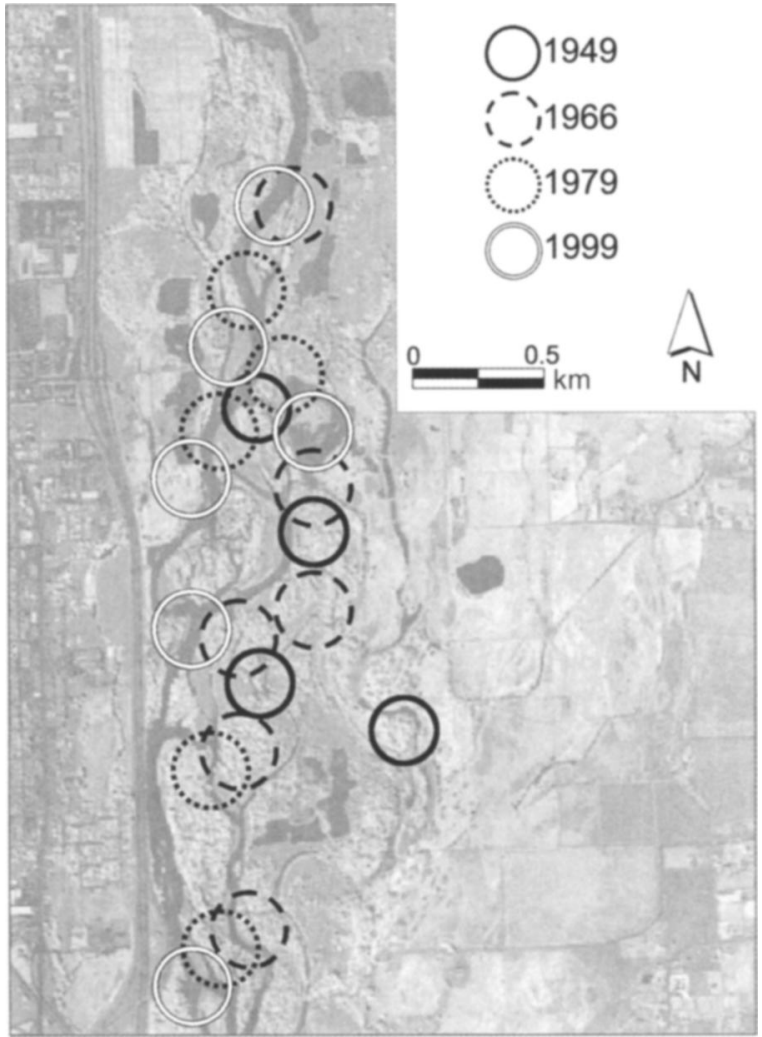

FIG. 9. A photograph derived from the 1999 multispectral imagery showing the positions of historical avulsion nodes determined from a sequence of aerial photographs beginning in 1927.

predict zones of deposition is also useful for evaluating likely areas where large wood would naturally deposit, thus providing a quantitative method for choosing where such material could be added to a river as part of a restoration effort. Mapping the floodplain in this manner could provide an additional tool to aid managers in prioritizing critical floodplain habitat for land acquisition, conservation easements, and a guide for restoration efforts. The idea is to focus attention to those areas of the floodplain having the best potential to maintain a high turnover rate of floodplain habitat. The degree of habitat turnover has been linked to ecosystem health as a disturbance mechanism that resets floodplain ecosystem structure and function resulting in greater biodiversity and complexity (Junk and Welcomme 1990, Stanford and Ward 1993, Arscott et al. 2000, Tockner and Stanford 2002, van der Nat et al. 2002, 2003, Ward et al. 2002).

\section{Comparison of historical avulsion nodes with modeled avulsion node position}

Aerial photographs from 1927, 1949, 1969, and 1979 were scanned and georectified to determine the location of historical avulsion nodes (Fig. 9). The water surface was digitized to delineate channel position and inun- dation extent. Historical avulsion nodes were determined by overlaying these time series, water-surface coverages and identifying areas where the river had developed new channels (Fig. 10). Between 1927 and 1999, 14 avulsion nodes were identified (Fig. 9) compared with six potential avulsion nodes identified using the remote sensing methodology presented here (Fig. 8 ). None of the modeled nodal positions overlaid precisely with historical ones but some were within several hundred meters of each other (Fig. 10).

Floodplain gravel mining played a role in some channel avulsion events between 1969 and 1979 as well as between 1979 and 1999 (Fig. 10). Bank erosion during flood events commonly results in "gravel pit-capture" of the main river channel throughout the Yakima River system (Norman et al. 1998). These "pit-capture" events result directly in channel avulsions that then disrupt the sediment supplies downstream, while the pit fills with gravel resulting in channel incision and loss of floodplain habitat related to the decrease in channel complexity.

Gravel-bed rivers continually reshape and rework their floodplains. Therefore, the position of an avulsion node is not totally dependent on the positions of historical nodes. Indeed, following a recent trip to the study reach, it was observed that the river had avulsed at the location of a predicted avulsion node sometime after the collection of ADP data in 2001 (Fig. 10). The main channel of the river now occupies a new location and the abandoned channel has become a small secondary channel. This recent avulsion location was predicted by the method presented but was not a location of a historical avulsion node.

\section{COnClusions}

Fluvial processes of cut and fill alluviation and channel avulsion are essential to maintaining the ecological health of a river system. These processes shape the floodplain landscape resulting in a continual shifting mosaic of habitats both above and belowground. Maintaining this shifting habitat mosaic is dependent on the ability of the river to move freely about the historical floodplain with sufficient power to rework the landscape. Our stepwise methodology objectively and quantitatively delineates floodplain areas having the highest potential to be reworked by fluvial processes. Historical aerial photo analysis or subjective walkover assessments lack the specificity for accurate floodplain delineation of potential geomorphic work zones. Spatially explicit modeling of water depth, flow velocity, shear stress, and stream power derived from surface hydraulic measurements combined with airborne multispectral remote sensing can accurately identify potential nodes of channel avulsion. This methodology also lends itself to predicting hot spots of bank erosion, evaluating depositional zones for sediment and large wood, quantifying sediment budgets, and identifying key areas where levies could be breached to reconnect 


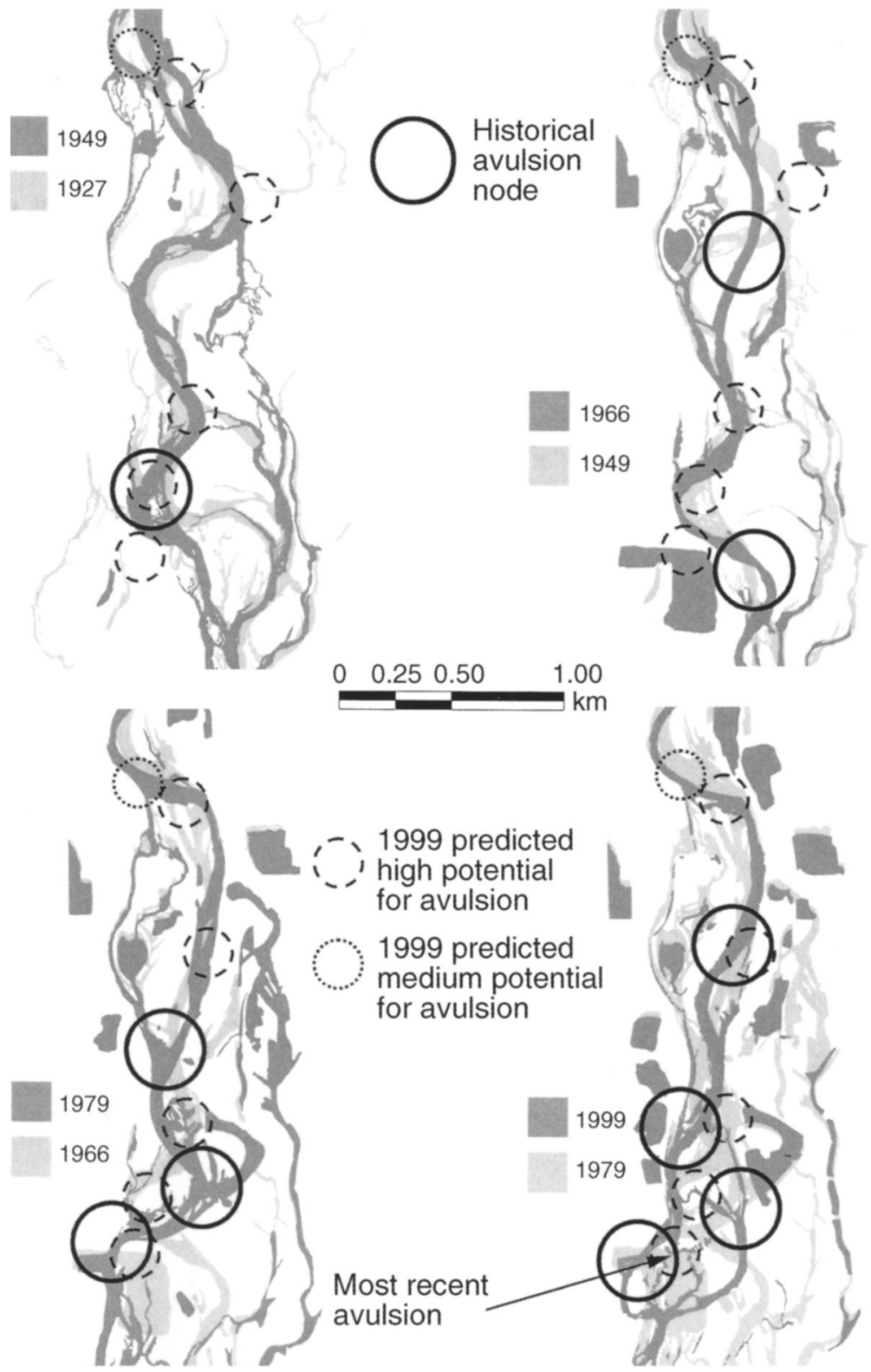

FIG. 10. A time-series sequence of historical avulsion node positions (black circles) compared with those predicted by the remote sensing methodology (dashed and dotted circles) presented here and corresponding to those shown in Fig. 9. The arrow points to the location of the most recent avulsion that corresponds to a predicted node position.

floodplains with the main river channel. Mapping the floodplain in this manner provides an additional tool to aid managers in prioritizing critical areas that have the highest restoration potential and to improve baseline assessment and monitoring. Ecologists can use the methodology as a basis for predicting floodplain structure response to flood events and for assessing habitat turnover rate.

The results of this study also demonstrate the utility of integrating existing remote sensing data with timelagged ground-based measures of flow hydraulics to model fluvial processes at relatively fine spatial reso- lutions over broad regional extents. Thus, by carefully examining discharge records and geomorphic changes, and collecting field data at similar flow conditions, archival imagery can be successfully used to model depth and velocity, as well as other floodplain habitats.

\section{ACKNOWLEDGMENTS}

This study was funded in part by the U.S. Bureau of Reclamation, Yakima District (Washington) and NSF Grant number EAR-0120523 Biocomplexity in the Environment-Dynamic Controls on Emergent Properties of River Flood Plains. Image mosaics were acquired and processed by Positive Systems, Incorporated, Whitefish, Montana, USA. Graeme Ag- 
gett, Central Washington University, Ellensburg, Washington, helped with the collection of ADP data. Two anonymous reviewers and J. S. Barron provided many useful comments that greatly improved the paper.

\section{Literature Cited}

Arscott, D. B., K. Tockner, and J. V. Ward. 2000. Aquatic habitat diversity along the corridor of an Alpine floodplain river (Fiume Tagliamento, Italy). Archiv für Hydrobiologie 49:679-704.

Bagnold, R. A. 1966. An approach to the sediment transport problem from general physics. U.S. Geological Survey Professional Paper 4221.

Braatne, J. H., S. B. Rood, and P. E. Heilman. 1996. Chapter 3: Life history, ecology and conservation of riparian cottonwoods in North America. Pages 57-85 in R. F. Stettler, J. H. D. Bradshaw, P. E. Heilman, and T. M. Hinckley, editors. Biology of Populus and its implications for management and conservation. National Research Council Canada, NRC Research Press, Ottawa, Canada.

Bradley, C. E., and D. G. Smith. 1986. Plains cottonwood recruitment and survival on a prairie meandering river floodplain, Milk River, southern Alberta and northern Mon tana. Canadian Journal of Botany 64:1433-1442.

Junk, W. J., and R. L. Welcomme. 1990. Floodplains. Pages 491-524 in B. C. Patten, editor. Wetlands and shallow continental water bodies. SPB Academic Publishing bv, The Hague, The Netherlands.

$\rightarrow$ Lorang, M. S., and F. R. Hauer. 2003. Flow competence and streambed stability: an evaluation of technique and application. Journal of the North American Benthological Society 22:475-491.

Mahoney, J. M., and S. B. Rood. 1998. Streamflow requirements for cottonwood seedling recruitment-an integrative model. Wetlands 18:634-645.

Naiman, R. J. 1998. Biotic stream classification. Pages 97119 in R. J. Naiman and R. E. Bilby, editors. River ecology and management: lessons from the Pacific Coastal Ecoregion. Springer-Verlag, New York, New York, USA.

Norman, D. K., C. F. Cederholm, and W. S. Lingley, Jr. 1998. Flood plains, salmon habitat, and sand and gravel mining. Washington Geology 26:3-20.

$\rightarrow$ Richter, B. D., and H. E. Richter. 2000. Prescribing flood regimes to sustain riparian ecosystems along meandering rivers. Conservation Biology 14:1467-1478.

Rood, S. B., and J. M. Mahoney. 1990. Collapse of riparian poplar forests downstream from dams in western prairies: probable causes and prospects for mitigation. Environmental Management 14:451-464.

Rood, S. B., J. M. Mahoney, D. E. Reid, and L. Zilm. 1995. Instream flows and the decline of riparian cottonwoods along the St. Mary River, Alberta. Canadian Journal of Botany 73:1250-1260.

Stanford, J. A. 1998. Rivers in the landscape: introduction to the special issue on riparian and groundwater ecology. Freshwater Biology 40:402-406.

$\rightarrow$ Stanford, J. A., and J. V. Ward. 1993. An ecosystem perspective of alluvial rivers: connectivity and the hyporheic corridor. Journal of the North American Benthological Society 12:48-60.

Stanford, J. A., J. V. Ward, W. J. Liss, C. A. Frissell, R. N. Williams, J. A. Lichatowich, and C. C. Coutant. 1996. A general protocol for restoration of regulated rivers. Regulated Rivers 12:391-413.

Tockner, K., and J. A. Stanford. 2002. Riverine flood plains: present state and future trends. Environmental Conservation 29:308-330.

Tou, J. T., and R. C. Gonzalez. 1977. Pattern recognition principles. Addison-Wesley, Reading, Massachusetts, USA.

van der Nat, D., A. P. Schmidt, K. Tockner, P. J. Edwards, and J. V. Ward. 2002. Inundation dynamics in braided floodplains: Tagliamento River, Northeast Italy. Ecosystems 5:636-647.

van der Nat, D., K. Tockner, P. J. Edwards, J. V. Ward, and A. M. Gurnell. 2003. Habitat change in braided flood plains (Tagliamento, NE Italy). Freshwater Biology 48:17991812.

Ward, J. V. 1997. An expansive perspective of riverine landscapes: pattern and process across scales. GAIA 6:52-60.

Ward, J. V., C. T. Robinson, and K. Tockner. 2002. Applicability of ecological theory to riverine ecosystems. Internationale Vereinigung für Theoretische und Angewandte Limnologie 28:443-450.

Ward, J. V., K. Tockner, and F. Schiemer. 1999. Biodiversity of floodplain river ecosystems: ecotones and connectivity. Regulated Rivers: Research and Management 15:125-139.

Whited, D. C., J. A. Stanford, and J. S. Kimball. 2002. Application of airborne multi-spectral digital imagery to characterize riverine habitats at different base flows. River Research and Applications 18:583-594.

Whited, D. C., J. A. Stanford, and J. S. Kimball. 2003. Application of airborne multispectral digital imagery to characterize the riverine habitat. Internationale Vereinigung für Theoretische und Angewandte Limnologie 28:1373-1380. 